\title{
Childhood leukaemia close to high-voltage power lines - the Geocap study, 2002-2007
}

\author{
C Sermage-Faure ${ }^{1,2}$, C Demoury ${ }^{1,2}$, J Rudant ${ }^{1,2,3}$, S Goujon-Bellec ${ }^{1,2,3}$, A Guyot-Goubin ${ }^{1,2,3}$, F Deschamps ${ }^{4}$, \\ D Hemon ${ }^{1,2}$ and J Clavel ${ }^{\star, 1,2,3}$ \\ ${ }^{1}$ Inserm, Center for Research in Epidemiology and Population Health (CESP), U1018, Environmental Epidemiology of Cancer \\ Team, Villejuif F-94807, France; ${ }^{2}$ Univ Paris-Sud, UMRS 1018, Villejuif F-94807, France; ${ }^{3}$ French National Registry of Childhood \\ Hematological Malignancies (NRCH), Villejuif, France and ${ }^{4}$ Réseau de Transport d'Electricité (RTE), Coeur Défense, 110 esplanade \\ du Général de Gaulle, La Defense 92030, France
}

Background: High-voltage overhead power lines (HVOLs) are a source of extremely low-frequency magnetic fields (ELF-MFs), which are classified as possible risk factors for childhood acute leukaemia (AL). The study was carried out to test the hypothesis of an increased AL incidence in children living close to HVOL of 225-400 kV (VHV-HVOL) and 63-150 kV (HV-HVOL).

Methods: The nationwide Geocap study included all the 2779 cases of childhood AL diagnosed in France over 2002-2007 and 30000 contemporaneous population controls. The addresses at the time of inclusion were geocoded and precisely located around the whole HVOL network.

Results: Increased odds ratios (ORs) were observed for AL occurrence and living within $50 \mathrm{~m}$ of a VHV-HVOL (OR=1.7 (0.9-3.6)). In contrast, there was no association with living beyond that distance from a VHV-HVOL or within $50 \mathrm{~m}$ of a HV-HVOL.

Conclusion: The present study, free from any participation bias, supports the previous international findings of an increase in AL incidence close to VHV-HVOL. In order to investigate for a potential role of ELF-MF in the results, ELF-MF at the residences close to HVOL are to be estimated, using models based on the annual current loads and local characteristics of the lines.

High-voltage overhead power lines (HVOLs) are one of the major sources of extremely low-frequency magnetic fields (ELF-MFs), considered a possible risk factor for childhood leukaemia. In the absence of any underlying biological hypothesis, the International Agency for Research on Cancer (IARC) classified ELF-MF as possible carcinogens (group 2B), based on epidemiological observations over more than two decades (IARC, 2002). The first meta-analyses concluded that exposure to ELF-MF levels of at least $0.3 \mu \mathrm{T}$ was significantly associated with an increased incidence of childhood acute leukaemia (AL) (odds ratio $(\mathrm{OR})=1.7(1.2-2.3$ ) for exposures $\geqslant 0.3 \mu \mathrm{T}$ (Greenland et al, 2000) and $\mathrm{OR}=2.0$ (1.3-3.3) for exposures $\geqslant 0.4 \mu \mathrm{T}$ (Ahlbom et al, 2000)). A recent meta-analysis of the studies published after 2000 (Kheifets et al, 2010) generated consistent but weaker results $(\mathrm{OR}=1.4(0.9-2.4)$ for exposures $\geqslant 0.3 \mu \mathrm{T}$ ). The large British study by Draper et al (2005) focused on the proximity of VHV-HVOL and showed an association between $\mathrm{AL}$ and residence at birth $<200 \mathrm{~m}$ from a VHV-HVOL $(\mathrm{OR}=1.7(1.1-2.5))$ and, to a lesser extent, between 200 and $600 \mathrm{~m}$ from a VHV-HVOL $(\mathrm{OR}=1.2(1.0-1.5))$. With the same data, the relative risk was not significantly increased for estimates of ELF-MF $\geqslant 0.4 \mu \mathrm{T}$ (Kroll et al, 2010). High-voltage overhead power lines account for only a fraction of ELF-MF exposure, but, in their near vicinity, constitute the main source of background exposure (Schüz et al, 2000; Maslanyj et al, 2007).

The aim of the present study was to test whether the risk of AL was increased in the vicinity of HVOL, where children were expected to encounter higher residential exposure to ELF-MF. We followed a two-step approach. The present one aims at investigating the relationship between $\mathrm{AL}$ and distance to HVOL. The second step will rely on calculated residential exposure to ELF-EMF based on characteristics of the neighbouring HVOL. The study, the first in France, was based on the geolocation of the last

*Correspondence: Dr J Clavel; E-mail: Jacqueline.Clavel@inserm.fr

Received 13 November 2012; revised 25 February 2013; accepted 2 March 2013; published online 4 April 2013

(c) 2013 Cancer Research UK. All rights reserved 0007-0920/13 
address and covered the entire mainland over a recent period (2002-2007), on an exhaustive basis, free from participation bias, and was based on a geographic information system (GIS) using precise and recent databases to locate the dwellings and HVOL.

\section{MATERIALS AND METHODS}

The Geocap case-control study. The Geocap case-control study included all the 2779 French childhood AL cases aged $<15$ years at the end of the year of diagnosis, diagnosed between 1 January 2002 and 31 December 2007, residing in mainland France (excluding Corsica for which HVOL information was not available). The cases were obtained from the French National Registry of Childhood Hematopoietic Malignancies (Lacour et al, 2010).

Over the same period (2002-2007), six yearly sets of 5000 control addresses were randomly sampled from the paediatric population of mainland France by the National Institute for Statistics and Economic Studies (INSEE), using the income and council tax databases of the French households. These databases contain the addresses and income information of all the households in France, irrespective of employment status, and list the children in each household by year of birth. The sample was stratified on the 94 French mainland administrative areas (Départements). The individual variables available for the controls were the year of birth, number of children in the household and last address. Demographic and socioeconomic characteristics of the municipality (Commune) of residence were also used as contextual variables. The sample of 30000 controls was closely representative of the source population in terms of age and number of children in the household, and in terms of contextual variables, that is, size of the urban unit, median income, proportion of blue-collar workers, proportion of subjects who successfully completed high school (baccalaureate holders) and proportion of homeowners in the Commune of residence (Sermage-Faure et al, 2012).

Geocoding. The residence considered for geolocation was the residence at the time of diagnosis for the cases and that at the time of inclusion for the controls. Residential histories, particularly addresses at birth, were not available. The method for geocoding the addresses of cases and controls was compiled, checked for consistency and corrected when necessary by GEOCIBLE, an outside service provider, in close cooperation with the epidemiology research team. The addresses were geocoded blind to case/control status, using the MAPINFO GIS, NAVTEQ street databases and detailed vectorized maps from the National Geographic Institute (IGN). Automatic processes were checked and completed by visual inspection of maps when necessary. Ultimately, only $3 \%$ of the cases and $1 \%$ of the controls could not be located more precisely than by their Commune of residence and were allocated the coordinates of their Commune town hall.

In the Navteq and IGN databases, the geocodes are given at the middle of the street in front of the number in the street (i.e., the front door, the entrance of the plot or the projection of centre of the plot along the street), generally corresponding to the mailbox residence. Most often in urban areas and in collective housing, the mailbox is attached to the building of residence. However, especially in countryside, the house can be at a distance from the entrance of the plot, where the mailbox is.

Depending on whether the databases enabled location of the home directly or by extrapolation from the nearest or more distant neighbours, the coordinates were assigned a degree of uncertainty along the street ranging from $20 \mathrm{~m}$ (exact number in the database) to the size of a Commune (Table 1). The scale of uncertainty provided by Geocible had been determined previously, based on the size of the objects to locate and on the mean differences between estimated and measured geocodes. The best geocoded
Table 1. Distribution of the cases and controls by category of uncertainty of location by geocoding

\begin{tabular}{|c|c|c|c|c|c|}
\hline \multirow[b]{2}{*}{$\begin{array}{l}\text { Category of } \\
\text { accuracy of } \\
\text { address location } \\
\text { for geocoding }\end{array}$} & \multirow[b]{2}{*}{ Uncertainty } & \multicolumn{2}{|c|}{ Cases } & \multicolumn{2}{|c|}{ Controls } \\
\hline & & $N$ & $\%$ & $N$ & $\%$ \\
\hline At the exact number & $20 \mathrm{~m}$ & 1946 & 70.0 & 23171 & 77.2 \\
\hline $\begin{array}{l}\text { In a section of a short } \\
\text { street }\end{array}$ & $50 \mathrm{~m}$ & 173 & 6.2 & 1658 & 5.5 \\
\hline At a close number & $100 \mathrm{~m}$ & 130 & 4.7 & 801 & 2.7 \\
\hline $\begin{array}{l}\text { In a medium street or } \\
\text { in a hamlet }\end{array}$ & $300 \mathrm{~m}$ & 394 & 14.2 & 3693 & 12.3 \\
\hline In a long street & $500 \mathrm{~m}$ & 54 & 1.9 & 383 & 1.3 \\
\hline In a Commune & & 82 & 3.0 & 292 & 1.0 \\
\hline Total & & 2779 & 100.0 & 30000 & 100.0 \\
\hline
\end{tabular}

addresses were assigned an uncertainty of $20 \mathrm{~m}$, equal to the mean value of the estimated coordinates given by the GIS and the center of the house. Altogether, 1946 cases (70\%) and 23171 controls (77\%) were located by their exact number in the street (best geocoded addresses, uncertainty of $20 \mathrm{~m}$ ), whereas 303 cases (11\%) and 2459 controls $(8.6 \%)$ were located by a segment of a short street or by a close number (uncertainty of 50-100 m).

In addition to the coordinates obtained for all the postal addresses of the Geocap sample, another set of coordinates was also estimated using photographic views obtained from Street View (Google Maps), Géoportail (IGN data) and the French cadaster, when available. This was possible for $72 \%$ of the cases and $69 \%$ of the controls living $<200 \mathrm{~m}$ from a HVOL, considering the uncertainty, and used to position the building of residence.

HVOL characteristics and distance from the nearest HVOL. There are $77400 \mathrm{~km}$ of HVOL in France. There are five main types: HVOL of $400 \mathrm{kV} \quad(13350 \mathrm{~km}), 225 \mathrm{kV} \quad(21200 \mathrm{~km}), \quad 150 \mathrm{kV}$ $(1050 \mathrm{~km})$ and 90 or $63 \mathrm{kV}(41800 \mathrm{~km})$. The HVOLs have been precisely mapped by RTE (Réseau de Transport d'Electricité), the French utility in charge of electricity transmission, based on the utility's own database, in which pylons and sections of lines are accurately located, and on the most precise local maps of the national geographic institute (IGN). The distances from the closest HVOLs were estimated by GEOCIBLE.

Statistical analysis. All the statistical analyses were performed using the SAS software package (version 9; SAS Institute Inc., Cary, NC, USA). The ORs, their $95 \%$ confidence intervals and two-sided $P$-values were estimated by unconditional logistic regression adjusted for age in 5-year categories and Département. Additional analyses stratified by age category were adjusted for age in years.

The subjects were classified in terms of their distance from the closest HVOL ( $<50,50-99,100-199,200-599$ and $\geqslant 600 \mathrm{~m})$. The very high voltage lines, 225 and $400 \mathrm{kV}$ (VHV-HVOL), and the high voltage lines, 63, 90 and $150 \mathrm{kV}$ (HV-HVOL), were separated as dwellings located $\leqslant 50 \mathrm{~m}$ from VHV-HVOL are expected to be more frequently exposed to higher ELF-MF than those located $\leqslant 50 \mathrm{~m}$ from HV-HVOL (Maslanyj et al, 2009). The inverse distance function was used to test for the existence of a trend in AL incidence, assigning 0 to the dwellings located at least $600 \mathrm{~m}$ from an HVOL.

All the main analyses were conducted on the whole study sample, without any selection by address uncertainty. The analyses 
Table 2. Description of the cases included in the study, by the distance between their residence and the closest HVOL and by voltage category (very high (225-400 kV) or high (63-150 kV)) over the period 2002-2007

\section{Distance from the closest HVOL}

\begin{tabular}{|c|c|c|c|c|c|c|c|}
\hline & \multicolumn{3}{|c|}{ 225-400 kV HVOL } & \multicolumn{3}{|c|}{ 63-150 kV HVOL } & \multirow[b]{2}{*}{ Total } \\
\hline & $0-49 \mathrm{~m}$ & $50-199 \mathrm{~m}$ & $\geqslant 200 \mathrm{~m}$ & $0-49 \mathrm{~m}$ & $50-199 \mathrm{~m}$ & $\geqslant 200 \mathrm{~m}$ & \\
\hline \multicolumn{8}{|l|}{ Gender } \\
\hline $\begin{array}{l}\text { Female } \\
\text { Male }\end{array}$ & $\begin{array}{l}4 \\
5\end{array}$ & $\begin{array}{l}12 \\
12\end{array}$ & $\begin{array}{l}1246 \\
1500\end{array}$ & $\begin{array}{l}7 \\
7\end{array}$ & $\begin{array}{l}26 \\
28\end{array}$ & $\begin{array}{l}1229 \\
1482\end{array}$ & $\begin{array}{l}1262 \\
1517\end{array}$ \\
\hline \multicolumn{8}{|l|}{ Age } \\
\hline $\begin{array}{l}<5 \text { years } \\
5-9 \text { years } \\
10-14 \text { years }\end{array}$ & $\begin{array}{l}6 \\
3 \\
0\end{array}$ & $\begin{array}{r}11 \\
10 \\
3\end{array}$ & $\begin{array}{r}1291 \\
858 \\
597 \\
\end{array}$ & $\begin{array}{l}8 \\
2 \\
4\end{array}$ & $\begin{array}{l}24 \\
18 \\
12 \\
\end{array}$ & $\begin{array}{r}1276 \\
851 \\
584 \\
\end{array}$ & $\begin{array}{r}1308 \\
871 \\
600 \\
\end{array}$ \\
\hline Down's syndrome & 0 & 0 & 43 & 0 & 0 & 43 & 43 \\
\hline \multicolumn{8}{|l|}{ AL type } \\
\hline$A L L$ & 8 & 21 & 2250 & 13 & 46 & 2220 & 2279 \\
\hline $\begin{array}{l}\text { B-cell precursor ALL } \\
\text { T-cell ALL } \\
\text { Other ALL }\end{array}$ & $\begin{array}{l}6 \\
0 \\
2\end{array}$ & $\begin{array}{r}12 \\
0 \\
9\end{array}$ & $\begin{array}{r}1056 \\
173 \\
1021\end{array}$ & $\begin{array}{l}8 \\
1 \\
4\end{array}$ & $\begin{array}{r}25 \\
4 \\
17\end{array}$ & $\begin{array}{r}1041 \\
168 \\
1011\end{array}$ & $\begin{array}{r}1074 \\
173 \\
1032\end{array}$ \\
\hline AML & 1 & 2 & 428 & 1 & 6 & 424 & 431 \\
\hline Other AL & 0 & 1 & 68 & 0 & 2 & 67 & 69 \\
\hline
\end{tabular}

were conducted on all the cases and also stratified by age group $<5$ years old covering most of the incidence peak and $\geqslant 5$ years old - and for acute lymphoblastic leukaemia (ALL) alone.

All the analyses were performed taking the same baseline as reference category, that is, the group of children who lived in Communes with no part of their territory within $600 \mathrm{~m}$ of a HVOL, after accounting for geocoding uncertainty. Thus, the baseline included all the residences definitely located $\geqslant 600 \mathrm{~m}$ from a HVOL, even if they were geocoded with the highest uncertainty. Additional sensitivity analyses also included the subjects living at least $600 \mathrm{~m}$ from a HVOL in the reference category, even when the Commune had a part of its territory within $600 \mathrm{~m}$ of a HVOL, in order to account for the possibility that the baseline category might select residences in relation with an $\mathrm{AL}$ risk factor.

The 67 cases and 203 controls who lived in a Commune partially located within $600 \mathrm{~m}$ of a line but who could not be individually located better than at the town hall were considered to have missing data for the distances from HVOL.

Supplementary analyses were performed to test the robustness of the results and account for the spatial extent of the house, by restriction to the best geocoded addresses (uncertainty $<20 \mathrm{~m}$ ), or by modifying the distance cutoffs around the a priori value of $50 \mathrm{~m}$ $(30,40,60$ and $70 \mathrm{~m})$. In addition, for sensitivity analyses, when the distances using the main geocoding and the photographic views were available, the cases and controls were classified in the category ' $<50 \mathrm{~m}$ from a HVOL', either when the distance from photographic views was $<50 \mathrm{~m}$, or when at least one of the two estimated distances was $<50 \mathrm{~m}$, or when both the estimated distances were $<50 \mathrm{~m}$.

The analyses were also stratified by contextual socioeconomic variables extracted from the 1999 census data for the Commune of residence, including the urban status of the Commune, median income of the households, proportion of blue-collar workers and proportion of baccalaureate holders. Additional analyses were performed after excluding the cases and controls who lived $<5 \mathrm{~km}$ from a nuclear power plant, in order to rule out possible confounding by residence in the proximity of a nuclear power plant, which was associated with AL in the present study (SermageFaure et al, 2012).

\section{RESULTS}

Table 2 describes the cases registered from 2002 to 2007 by age, gender and leukaemia subtype, on the basis of the distance of their residences from the closest VHV-HVOL or HV-HVOL.

The 610 cases $(22.0 \%)$ and 7061 controls (23.5\%) who were living in a Commune entirely located at least $600 \mathrm{~m}$ from any HVOL constituted the baseline of the models. Living within $50 \mathrm{~m}$ of the closest HVOL, all voltages considered together, was not associated with $\mathrm{AL}(\mathrm{OR}=1.2(0.8-1.9))$ (Table 3). However, while no association was observed with residences close to HV-HVOL $(\mathrm{OR}=1.0(0.6-1.7))$, an association was evidenced for children who lived within $50 \mathrm{~m}$ of a VHV-HVOL $(\mathrm{OR}=1.7(0.9-3.6))$. In contrast, the ORs were close to one for the residences located $\geqslant 50 \mathrm{~m}$ from a HVOL, even a VHV-HVOL, and no statistically significant trend was observed with the inverse of the distance $(P=0.28$ for distance from VHV-HVOL). The results for ALL were very similar $(\mathrm{OR}=1.9(0.9-4.0)$ at $<50 \mathrm{~m}$ from a VHVHVOL).

Splitting the sample into children aged $<5$ years and those aged $\geqslant 5$ years showed that the association was only observed for the younger group (Table 4 ). In that age group, living within $50 \mathrm{~m}$ of the closest VHV-HVOL was significantly associated with $\mathrm{AL}$ $(\mathrm{OR}=2.6(1.0-7.0))$, with a significant trend with the inverse of the distance $(P=0.03)$, whereas there was no association for the older group $(\mathrm{OR}=1.0(0.3-3.3)$ living within $50 \mathrm{~m}$ of the closest VHV-HVOL).

Living within $50 \mathrm{~m}$ of a VHV-HVOL was not associated with $\mathrm{AL}$ in the Communes of urban units with a population $>100000$ 
Table 3. Association between childhood acute leukaemia and distance to the closest HVOL by category of voltage (very high (225-400 kV) or high (63-150 kV)) over the period 2002-2007

Distance to $\mathrm{HVOL}$

\begin{tabular}{|c|c|c|c|c|c|c|c|c|c|c|c|c|c|c|c|c|c|c|}
\hline & \multicolumn{6}{|c|}{ 225-400 kV HVOL } & \multicolumn{6}{|c|}{ 63-150 kV HVOL } & \multicolumn{6}{|c|}{ Any HVOL } \\
\hline & \multicolumn{2}{|c|}{ Cases } & \multicolumn{2}{|c|}{ Controls } & \multirow[b]{2}{*}{$\mathrm{OR}^{\mathrm{a}}$} & \multirow[b]{2}{*}{$95 \% \mathrm{Cl}$} & \multicolumn{2}{|c|}{ Cases } & \multicolumn{2}{|c|}{ Controls } & \multirow[b]{2}{*}{$\mathrm{OR}^{\mathrm{a}}$} & \multirow[b]{2}{*}{$95 \% \mathrm{Cl}$} & \multicolumn{2}{|c|}{ Cases } & \multicolumn{2}{|c|}{ Controls } & \multirow[b]{2}{*}{$\mathrm{OR}^{\mathrm{a}}$} & \multirow[b]{2}{*}{$95 \% \mathrm{Cl}$} \\
\hline & $n$ & $\%$ & $n$ & $\%$ & & & $n$ & $\%$ & $n$ & $\%$ & & & $n$ & $\%$ & $n$ & $\%$ & & \\
\hline Baseline $^{\mathbf{b}}$ & 610 & 22.0 & 7061 & 23.5 & 1.0 & Reference & 610 & 22.0 & 7061 & 23.5 & 1.0 & Reference & 610 & 22.0 & 7061 & 23.5 & 1.0 & Reference \\
\hline Unknown & 67 & & 203 & & & & 67 & & 203 & & & & 67 & & 203 & & & \\
\hline$\geqslant 600 m$ & 1924 & 69.2 & 20896 & 69.7 & 1.0 & $(0.9-1.2)$ & 1792 & 64.5 & 19168 & 63.9 & 1.1 & $(1.0-1.2)$ & 1665 & 59.9 & 17937 & 59.8 & 1.1 & $(0.9-1.2)$ \\
\hline $200-599 m$ & 145 & 5.2 & 1416 & 4.7 & 1.2 & $(1.0-1.4)$ & 242 & 8.7 & 2740 & 9.1 & 1.0 & $(0.8-1.2)$ & 345 & 12.4 & 3633 & 12.1 & 1.1 & $(0.9-1.2)$ \\
\hline $100-199 \mathrm{~m}$ & 16 & 0.6 & 267 & 0.9 & 0.7 & $(0.4-1.2)$ & 33 & 1.2 & 461 & 1.5 & 0.8 & $(0.6-1.2)$ & 44 & 1.6 & 669 & 2.2 & 0.8 & $(0.5-1.0)$ \\
\hline 50-99 m & 8 & 0.3 & 97 & 0.3 & 1.0 & $(0.5-2.1)$ & 21 & 0.8 & 203 & 0.7 & 1.2 & $(0.7-1.9)$ & 25 & 0.9 & 284 & 0.9 & 1.0 & $(0.7-1.6)$ \\
\hline $0-49 \mathrm{~m}$ & 9 & 0.3 & 60 & 0.2 & 1.7 & $(0.9-3.6)$ & 14 & 0.5 & 164 & 0.5 & 1.0 & $(0.6-1.7)$ & 23 & 0.8 & 213 & 0.7 & 1.2 & $(0.8-1.9)$ \\
\hline Total & 2779 & & 30000 & & & & 2779 & & 30000 & & & & 2779 & & 30000 & & & \\
\hline
\end{tabular}

Abbreviations: $\mathrm{Cl}=$ confidence interval; $\mathrm{HVOL}=$ high-voltage overhead power line; $\mathrm{OR}=$ odds ratio.

${ }^{\mathrm{a}} \mathrm{OR}$ and $95 \% \mathrm{Cls}$ estimated by logistic regression adjusted for age at the end of the year (5-year age groups for the 0-14-year-old children, 1-year age groups for the 0-4-year-old children) and Département of residence.

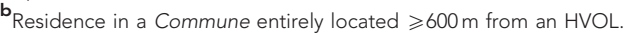

(Table 4), but an association was observed for the less urban categories of Commune. The same pattern was observed for the under-5-year age group (data not shown). The association between AL and living $<50 \mathrm{~m}$ from a VHV-HVOL appeared more marked, although not significantly so, in the Communes with less-favorable contextual socioeconomic characteristics: median income or percentage baccalaureate holders lower than the median value for the controls; percentage blue-collar workers greater than the median value for the controls. Adjustments for those contextual variables, either separately or jointly, did not change the estimates.

No case and only two controls lived within $5 \mathrm{~km}$ of a nuclear power plant and $<200 \mathrm{~m}$ from a VHV-HVOL; excluding them did not modify the results.

Sensitivity analyses restricted to the best geocoded subjects (uncertainty $\leqslant 20 \mathrm{~m}$ ) generated slightly stronger results $(\mathrm{OR}=2.1$ (0.9-4.7) for living within $50 \mathrm{~m}$ of a VHV-HVOL) (Table 5). The results were also unchanged when the cutoffs were 10 and $20 \mathrm{~m}$ above or below the a priori value of $50 \mathrm{~m}$, and when the baseline was extended to include the subjects living $>600 \mathrm{~m}$ from a HVOL, even if their Commune of residence had parts located $<600 \mathrm{~m}$ from a line (data not shown). Lastly, in the sensitivity analyses using the main geocoding distance and that based on photographic views when both were available (Table 5), the ORs remained of the same order of magnitude but the associations were no longer significant $(\mathrm{OR}=1.3(0.5-3.7)$ for distance $<50 \mathrm{~m}$ based on photographic views, $\mathrm{OR}=1.7(0.6-4.8)$ for both distances $<50 \mathrm{~m}$ and $\mathrm{OR}=1.5(0.8-3.1)$ for at least one distance $<50 \mathrm{~m}$ from a VHV-HVOL). For 0-4-year-old children, this was also the case $(\mathrm{OR}=2.5(0.6-10.5)$ for distance $<50 \mathrm{~m}$ based on photographic views, $\mathrm{OR}=3.5(0.8-15.1)$ for both distances $<50 \mathrm{~m}$ and $\mathrm{OR}=2.3(0.9-6.0)$ for at least one distance $<50 \mathrm{~m})$.

\section{DISCUSSION}

The present analysis of the Geocap nationwide case-control study was carried out to test the hypothesis that living close to HVOL, particularly VHV-HVOL, was associated with an increased incidence of childhood AL. The study focused on HVOL, a major source of exposure to ELF-MF in neighbouring residences (Schüz et al, 2000; Maslanyj et al, 2007). The proximity of HVOL to the residence of all the subjects was reliably evaluated without any selection and using the same process over all mainland France and over the 2002-2007 period. The results for living $<50 \mathrm{~m}$ from a 225 or $400 \mathrm{kV}$ HVOL were compatible with the IARC conclusions. There was no association beyond that distance. The association at a short distance was not observed for children aged $\geqslant 5$ years or those living in the most urban Communes.

The study covered a recent and relatively short period, and historical databases were therefore available for the entire period. One of the main strengths of the Geocap study is that it was designed to avoid selection biases. The cases were identified by the national registry, which complies with the international criteria required for cancer registration and classification, and achieves a high degree of completeness, by active research with almost three sources per case on average (Clavel et al, 2004; Lacour et al, 2010). Similarly, the recruitment of the controls did not require their active participation, preventing self-selection by socioeconomic status. De facto, the control sample was closely representative of the paediatric population on the basis of the sociodemographic contextual criteria (Table 1).

All the cases' and controls' addresses were obtained and geocoded, and the distances were calculated from objective databases free from any recall bias and blind to case/control status. This is another strength of the Geocap study in that it enabled minimisation of differential misclassifications. The distances estimated from the GISs were assumed to rank, as adequately as possible, the cases and controls by the true distance of their dwellings from the HVOL. The databases used to locate the lines were very precise. In particular, pylons were located with an uncertainty of $2.5 \mathrm{~m}$ in the RTE database.

Interestingly, the results were strengthened when the analyses were restricted to the best geocoded addresses. The 67 cases and 203 controls $(<2 \%$ of the subjects) whose addresses were not precise enough to enable their location close to the HVOL probably had no substantial impact on the results, given the expected distribution of the few subjects with respect to the distance from VHV-HVOL (about $0.2 \%$ of the controls $<50 \mathrm{~m}$ from VHV-HVOL). For the association to have been due to the 
Table 4. Association between childhood AL and distance from HVOLs over the period 2002-2007, stratified by age and urban status of the Commune of residence

Address-based distance from HVOL

\begin{tabular}{|c|c|c|c|c|c|c|c|c|c|c|c|}
\hline \multicolumn{6}{|c|}{ 225-400 kV HVOL } & \multicolumn{6}{|c|}{ 63-150 kV HVOL } \\
\hline \multicolumn{2}{|c|}{$\mathrm{Ca}$} & \multicolumn{2}{|c|}{ Co } & \multirow[t]{2}{*}{$\mathrm{OR}^{\mathrm{a}}$} & \multirow[t]{2}{*}{$95 \% \mathrm{Cl}$} & \multicolumn{2}{|c|}{$\mathrm{Ca}$} & \multicolumn{2}{|c|}{ Co } & \multirow[t]{2}{*}{ OR $^{a}$} & \multirow[t]{2}{*}{$95 \% \mathrm{Cl}$} \\
\hline$n$ & $\%$ & $n$ & $\%$ & & & $n$ & $\%$ & $n$ & $\%$ & & \\
\hline
\end{tabular}

\begin{tabular}{|c|c|c|c|c|c|c|c|c|c|c|c|c|}
\hline \multicolumn{13}{|l|}{ Age } \\
\hline \multicolumn{13}{|l|}{$0-4$ years } \\
\hline Baseline $^{\mathbf{b}}$ & 311 & 23.8 & 2326 & 23.9 & 1.0 & Reference & 311 & 23.8 & 2326 & 23.9 & 1.0 & Reference \\
\hline Unknown & 35 & & 85 & & & & 35 & & 85 & & & \\
\hline$\geqslant 600 \mathrm{~m}$ & 870 & 66.6 & 6734 & 69.3 & 0.9 & $(0.8-1.1)$ & 814 & 62.3 & 6146 & 63.2 & 0.9 & $(0.8-1.1)$ \\
\hline $200-599 m$ & 74 & 5.7 & 444 & 4.6 & 1.2 & $(0.9-1.6)$ & 115 & 8.8 & 902 & 9.3 & 0.9 & $(0.7-1.1)$ \\
\hline $100-199 m$ & 5 & 0.4 & 87 & 0.9 & 0.4 & $(0.2-1.0)$ & 13 & 1.0 & 145 & 1.5 & 0.6 & $(0.4-1.2)$ \\
\hline $50-99 m$ & 6 & 0.5 & 27 & 0.3 & 1.6 & $(0.7-4.1)$ & 11 & 0.8 & 61 & 0.6 & 1.3 & $(0.7-2.5)$ \\
\hline $0-49 \mathrm{~m}$ & 6 & 0.5 & 14 & 0.1 & 2.6 & $(1.0-6.9)$ & 8 & 0.6 & 52 & 0.5 & 1.1 & $(0.5-2.3)$ \\
\hline Total & 1307 & & 9717 & & & & 1307 & & 9717 & & & \\
\hline \multicolumn{13}{|l|}{$5-14$ years } \\
\hline Baseline $^{b}$ & 299 & 20.3 & 4735 & 23.3 & 1.0 & Reference & 299 & 20.8 & 4735 & 23.3 & 1.0 & Reference \\
\hline Unknown & 32 & & 118 & & & & 32 & & 118 & & & \\
\hline$\geqslant 600 \mathrm{~m}$ & 1054 & 71.6 & 14162 & 69.8 & 1.2 & $(1.0-1.4)$ & 978 & 66.4 & 13022 & 64.2 & 1.2 & $(1.0-1.4)$ \\
\hline $200-599 m$ & 71 & 4.8 & 972 & 4.8 & 1.2 & $(0.9-1.5)$ & 127 & 8.6 & 1838 & 9.1 & 1.1 & $(0.9-1.4)$ \\
\hline $100-199 \mathrm{~m}$ & 11 & 0.7 & 180 & 0.9 & 1.0 & $(0.5-1.8)$ & 20 & 1.4 & 316 & 1.6 & 1.0 & $(0.6-1.6)$ \\
\hline 50-99 m & 2 & 0.1 & 70 & 0.3 & 0.5 & $(0.1-2.0)$ & 10 & 0.7 & 142 & 0.7 & 1.1 & $(0.6-2.1)$ \\
\hline $0-49 \mathrm{~m}$ & 3 & 0.2 & 46 & 0.2 & 1.0 & $(0.3-3.3)$ & 6 & 0.4 & 112 & 0.6 & 0.9 & $(0.4-2.1)$ \\
\hline Total & 1472 & & 20283 & & & & 1472 & & 20283 & & & \\
\hline
\end{tabular}

Size of urban unit ${ }^{c}$

\begin{tabular}{|c|c|c|c|c|c|c|c|c|c|c|c|c|}
\hline \multicolumn{13}{|c|}{$<5000$ inhabitants } \\
\hline Baseline $^{b}$ & 309 & 34.1 & 3415 & 35.5 & 1.0 & Reference & 309 & 34.1 & 3415 & 35.5 & 1.0 & Reference \\
\hline Unknown & 36 & & 67 & & & & 36 & & 67 & & & \\
\hline$\geqslant 600 \mathrm{~m}$ & 525 & 57.9 & 5630 & 58.6 & 1.0 & $(0.9-1.2)$ & 482 & 53.1 & 5221 & 54.3 & 1.0 & $(0.9-1.2)$ \\
\hline $200-599 m$ & 30 & 3.3 & 393 & 4.1 & 0.9 & $(0.6-1.3)$ & 68 & 7.5 & 724 & 7.5 & 1.0 & $(0.8-1.4)$ \\
\hline 100-199 m & 2 & 0.2 & 71 & 0.7 & 0.3 & $(0.1-1.4)$ & 7 & 0.8 & 109 & 1.1 & 0.7 & $(0.3-1.6)$ \\
\hline $50-99 m$ & 1 & 0.1 & 20 & 0.2 & 0.6 & $(0.1-4.6)$ & 4 & 0.4 & 45 & 0.5 & 1.1 & $(0.4-3.0)$ \\
\hline $0-49 \mathrm{~m}$ & 4 & 0.4 & 19 & 0.2 & 2.5 & $(0.8-7.7)$ & 1 & 0.1 & 34 & 0.4 & 0.4 & $(0.1-2.9)$ \\
\hline Total & 907 & & 9615 & & & & 907 & & 9615 & & & \\
\hline
\end{tabular}

5000-100 000 inhabitants

\begin{tabular}{|c|c|c|c|c|c|c|c|c|c|c|c|c|}
\hline Baseline $^{b}$ & 71 & 11.1 & 756 & 10.9 & 1.0 & Reference & 71 & 11.1 & 756 & 10.9 & 1.0 & Reference \\
\hline Unknown & 18 & & 63 & & & & 18 & & 63 & & & \\
\hline$\geqslant 600 \mathrm{~m}$ & 513 & 80.3 & 5811 & 84.1 & 0.8 & $(0.6-1.1)$ & 451 & 72.7 & 4942 & 71.6 & 0.9 & $(0.7-1.2)$ \\
\hline $200-599 m$ & 27 & 4.2 & 219 & 3.2 & 1.2 & $(0.7-2.0)$ & 72 & 11.5 & 876 & 12.7 & 0.8 & $(0.5-1.1)$ \\
\hline 100-199 m & 5 & 0.8 & 33 & 0.5 & 1.5 & $(0.5-3.9)$ & 15 & 2.4 & 144 & 2.1 & 1.0 & $(0.5-1.8)$ \\
\hline $50-99 m$ & 1 & 0.2 & 19 & 0.3 & 0.6 & $(0.1-4.8)$ & 5 & 0.8 & 73 & 1.1 & 0.7 & $(0.3-1.7)$ \\
\hline $0-49 \mathrm{~m}$ & 4 & 0.6 & 6 & 0.1 & 4.9 & $(1.3-19.2)$ & 7 & 1.1 & 53 & 0.8 & 1.2 & $(0.5-2.7)$ \\
\hline Total & 639 & & 6907 & & & & 639 & & 6907 & & & \\
\hline \multicolumn{13}{|c|}{$\geqslant 100000$ inhabitants } \\
\hline Baseline $^{\mathbf{b}}$ & 230 & 18.7 & 2890 & 21.4 & 1.0 & Reference & 230 & 18.7 & 2890 & 21.4 & 1.0 & Reference \\
\hline Unknown & 13 & & 73 & & & & 13 & & 73 & & & \\
\hline$\geqslant 600 m$ & 886 & 71.9 & 9455 & 70.2 & 1.1 & $(0.9-1.4)$ & 859 & 69.7 & 9005 & 66.8 & 1.2 & $(0.9-1.4)$ \\
\hline $200-599$ m & 88 & 7.1 & 804 & 6.0 & 1.3 & $(1.0-1.8)$ & 102 & 8.3 & 1140 & 8.5 & 1.1 & $(0.8-1.4)$ \\
\hline $100-199$ m & 9 & 0.7 & 163 & 1.2 & 0.7 & $(0.4-1.4)$ & 11 & 0.9 & 208 & 1.5 & 0.7 & $(0.4-1.3)$ \\
\hline 50-99 m & 6 & 0.5 & 58 & 0.4 & 1.4 & $(0.6-3.3)$ & 12 & 1.0 & 85 & 0.6 & 1.7 & $(0.9-3.3)$ \\
\hline $0-49 \mathrm{~m}$ & 1 & 0.1 & 35 & 0.3 & 0.4 & $(0.1-2.9)$ & 6 & 0.5 & 77 & 0.6 & 1.0 & $(0.4-2.4)$ \\
\hline Total & 1233 & & 13478 & & & & 1233 & & 13478 & & & \\
\hline
\end{tabular}

Abbreviations: $\mathrm{AL}=$ acute leukaemia; $\mathrm{Ca}=$ number of cases; $\mathrm{Cl}=$ confidence interval; $\mathrm{Co}=$ number of controls; $\mathrm{HVOL}=$ high-voltage overhead power line; $\mathrm{OR}=\mathrm{odds}$ ratio.

${ }^{\mathrm{a}} \mathrm{ORs}$ and $95 \% \mathrm{Cls}$ estimated by logistic regression adjusted for age at the end of the year (5-year age groups for the 0-14-year-old children, 1-year age groups for the 0-4-year-old children) and Département of residence.

$\mathbf{b}_{\text {Baseline }}=$ residence in a Commune entirely located $\geqslant 600 \mathrm{~m}$ from any HVOL.

${ }^{c}$ An urban unit is defined by the INSEE (National Institute of Statistics and Economic Studies) as a group of Communes in which the distance between dwellings is nowhere more than $200 \mathrm{~m}$. 
Table 5. Sensitivity analyses of the association between childhood acute leukaemia and distance to the closest HVOL by category of voltage (very high (225-400 kV) or high (63-150 kV)) over the period 2002-2007, for all ages and the 0-4-years age group

Main results

Sensitivity analyses

\begin{tabular}{|c|c|c|c|c|c|c|c|c|c|c|c|c|c|c|c|c|c|c|c|c|}
\hline & \multicolumn{4}{|c|}{ Main results } & \multicolumn{16}{|c|}{ Sensitivity analyses } \\
\hline & \multicolumn{4}{|c|}{ GIS with any uncertainty } & \multicolumn{4}{|c|}{$\begin{array}{c}\text { (1) GIS with } \\
\text { uncertainty of } 20 \mathrm{~m}\end{array}$} & \multicolumn{12}{|c|}{ (2) Photographic views available } \\
\hline & \multirow[b]{2}{*}{$\mathrm{Ca}$} & \multirow[b]{2}{*}{ Co } & \multirow[b]{2}{*}{ OR } & \multirow[b]{2}{*}{$95 \% \mathrm{Cl}$} & \multirow[b]{2}{*}{$\mathrm{Ca}$} & \multirow[b]{2}{*}{ Co } & \multirow[b]{2}{*}{ OR } & \multirow[b]{2}{*}{$95 \% \mathrm{Cl}$} & \multicolumn{4}{|c|}{ Photograph only } & \multicolumn{4}{|c|}{$<50 \mathrm{~m}$ by GIS or photo } & \multicolumn{4}{|c|}{$<50 \mathrm{~m}$ by GIS and photo } \\
\hline & & & & & & & & & $\mathrm{Ca}$ & Co & OR & $95 \% \mathrm{Cl}$ & $\mathrm{Ca}$ & Co & OR & $95 \% \mathrm{Cl}$ & $\mathrm{Ca}$ & Co & OR & $95 \% \mathrm{Cl}$ \\
\hline \multicolumn{21}{|c|}{$0-14$ years } \\
\hline Baseline & 610 & 7061 & 1.0 & Reference & 610 & 7061 & 1.0 & Reference & 610 & 7061 & 1.0 & \begin{tabular}{|l|l} 
Reference \\
\end{tabular} & 610 & 7061 & 1.0 & Reference & 610 & 7061 & 1.0 & Reference \\
\hline \multicolumn{21}{|l|}{ Any HVOL } \\
\hline $100-199 \mathrm{~m}$ & 44 & 669 & 0.8 & $(0.5-1.0)$ & 32 & 499 & \begin{tabular}{|l|l|}
0.7 \\
\end{tabular} & \begin{tabular}{|l|l|}
$(0.5-1.1)$ \\
\end{tabular} & 36 & 455 & 0.9 & $(0.6-1.3)$ & & & & & & & & \\
\hline $50-99 \mathrm{~m}$ & 25 & 284 & 1.0 & $(0.7-1.6)$ & 20 & 212 & \begin{tabular}{|l|}
1.1 \\
\end{tabular} & $(0.7-1.8)$ & 22 & 184 & 1.4 & $(0.9-2.2)$ & & & & & & & & \\
\hline $0-49 m$ & 23 & 213 & 1.2 & $(0.8-1.9)$ & 16 & 152 & 1.2 & $(0.7-2.0)$ & 14 & 158 & 1.1 & $(0.6-1.9)$ & 24 & 243 & 1.2 & $(0.7-1.8)$ & 13 & 128 & 1.2 & $(0.7-2.1)$ \\
\hline \multicolumn{21}{|l|}{ VHV-HVOL } \\
\hline $100-199 m$ & 16 & 267 & 0.7 & $(0.4-1.2)$ & 13 & 200 & 0.8 & \begin{tabular}{|l|l|}
$(0.4-1.3)$ \\
\end{tabular} & 18 & 172 & 1.2 & $(0.7-1.9)$ & & & & & & & & \\
\hline $50-99 \mathrm{~m}$ & 8 & 97 & 1.0 & $(0.5-2.1)$ & 6 & 68 & 1.0 & $(0.4-2.4)$ & 8 & 74 & 1.3 & $(0.6-2.7)$ & & & & & & & & \\
\hline $0-49 \mathrm{~m}$ & 9 & 60 & 1.7 & $(0.9-3.6)$ & 7 & 39 & 2.1 & $(0.9-4.7)$ & 4 & 38 & 1.3 & $(0.5-3.7)$ & 9 & 68 & 1.5 & $(0.8-3.1)$ & 4 & 30 & 1.7 & $(0.6-4.8)$ \\
\hline \multicolumn{21}{|l|}{ HV-HVOL } \\
\hline $100-199 \mathrm{~m}$ & 33 & 461 & 0.8 & $(0.6-1.2)$ & 22 & 346 & \begin{tabular}{|l|}
0.7 \\
\end{tabular} & \begin{tabular}{|l|l|}
$(0.5-1.1)$ \\
\end{tabular} & 24 & 322 & 0.9 & $(0.6-1.3)$ & & & & & & & & \\
\hline $50-99 \mathrm{~m}$ & 21 & 203 & 1.2 & $(0.7-1.9)$ & 16 & 155 & 1.2 & $(0.7-2.0)$ & 14 & 121 & 1.3 & $(0.7-2.3)$ & & & & & & & & \\
\hline $0-49 m$ & 14 & 164 & 1.0 & $(0.6-1.7)$ & 9 & 120 & 0.8 & $(0.4-1.7)$ & 10 & 127 & 0.9 & $(0.5-1.8)$ & 15 & 188 & 0.9 & $(0.5-1.6)$ & 9 & 103 & 1.0 & $(0.5-2.0)$ \\
\hline \multicolumn{21}{|l|}{$0-4$ years } \\
\hline Baseline & 311 & 2326 & 1.0 & Reference & 311 & 2326 & 1.0 & Reference & 311 & 2326 & 1.0 & \begin{tabular}{|l|} 
Reference \\
\end{tabular} & 311 & 2326 & 1.0 & \begin{tabular}{|l|} 
Reference \\
\end{tabular} & 311 & 2326 & 1.0 & Reference \\
\hline \multicolumn{21}{|l|}{ Any HVOL } \\
\hline $100-199 m$ & 17 & 213 & 0.6 & $(0.3-1.0)$ & 9 & 160 & 0.4 & \begin{tabular}{|l|}
$(0.2-0.8)$ \\
\end{tabular} & 16 & 146 & 0.9 & $(0.5-1.5)$ & & & & & & & & \\
\hline $50-99 \mathrm{~m}$ & 14 & 84 & 1.2 & $(0.7-2.1)$ & 11 & 62 & 1.2 & $(0.6-2.4)$ & 13 & 55 & 1.7 & $(0.9-3.3)$ & & & & & & & & \\
\hline $0-49 \mathrm{~m}$ & 14 & 62 & 1.5 & $(0.8-2.8)$ & 9 & 42 & 1.3 & $(0.6-2.8)$ & 8 & 38 & 1.5 & $(0.6-3.3)$ & 14 & 66 & 1.4 & $(0.8-2.6)$ & 8 & 34 & 1.7 & $(0.8-3.9)$ \\
\hline \multicolumn{21}{|l|}{ VHV-HVOL } \\
\hline $100-199 \mathrm{~m}$ & 5 & 87 & 0.4 & $(0.2-1.0)$ & 4 & 63 & 0.5 & \begin{tabular}{|l|}
$(0.2-0.4)$ \\
\end{tabular} & 9 & 58 & 1.3 & $(0.6-2.8)$ & & & & & & & & \\
\hline $50-99 \mathrm{~m}$ & 6 & 27 & 1.6 & $(0.7-4.1)$ & 4 & 19 & 1.6 & $(0.5-5.0)$ & 6 & 21 & 2.1 & $(0.8-5.8)$ & & & & & & & & \\
\hline $0-49 m$ & 6 & 14 & 2.6 & $(1.0-6.9)$ & 5 & 8 & 4.1 & $(1.3-13.3)$ & 3 & 7 & 2.5 & $(0.6-10.5)$ & 6 & 16 & 2.3 & $(0.9-6.0)$ & 3 & 5 & 3.5 & $(0.8-15.1)$ \\
\hline HV-HVOL & & & & & & & & & & & & & & & & & & & & \\
\hline $100-199 m$ & 13 & 108 & 0.6 & $(0.4-1.2)$ & 6 & 145 & \begin{tabular}{|l|}
$\mid$ \\
\end{tabular} & \begin{tabular}{|l|}
$(0.2-0.9)$ \\
\end{tabular} & 10 & 99 & 0.7 & $(0.4-1.4)$ & & & & & & & & \\
\hline $50-99 \mathrm{~m}$ & 11 & 45 & 1.3 & $(0.7-2.5)$ & 8 & 61 & 1.2 & $(0.5-2.6)$ & 7 & 35 & 1.5 & $(0.6-3.4)$ & & & & & & & & \\
\hline $0-49 \mathrm{~m}$ & 8 & 36 & 1.1 & $(0.5-2.3)$ & 4 & 52 & 0.6 & $(0.2-1.8)$ & 5 & 33 & 1.1 & $(0.4-2.9)$ & 8 & 55 & 1.0 & $(0.5-2.1)$ & 5 & 30 & 1.3 & $(0.5-3.4)$ \\
\hline
\end{tabular}

Unknown category, the true addresses would have to have been within $50 \mathrm{~m}$ of a VHV-HVOL for none of the unclassified cases and for about $15 \%$ of the unclassified controls, which is very unlikely. The sensitivity analyses were consistent with the main results.

The Geocap study was designed to avoid selection and differential misclassification biases, which are common shortcomings of case-control studies on environmental factors, particularly ELF-MF (Mezei and Kheifets, 2006; Kheifets and Oksuzyan, 2008; Schüz and Ahlbom, 2008). The study included no individual data other than age and address, which were obtained for all the cases and controls. Therefore, potential AL risk factors such as birth order, breastfeeding, day-care attendance and pesticide exposure were not available. However, conditionally on age and the sociodemographic characteristics of the Commune of residence, which were accounted for in adjusted or stratified analyses, known or suspected risk factors are not likely to differ markedly within $v s$ outside the 50-m distance from the VHVHVOL. The study may have suffered from non-differential misclassifications, particularly because of the uncertainty of the geolocation of the homes, or because the period considered, that is, residence at diagnosis or interview, may not belong to the most relevant time window, or because the small numbers did not enable separation of the 400- and 225-kV VHV-HVOL or splitting the smallest category of distance. Therefore, the relationship between living close to VHV-HVOL and AL is probably not overestimated. As a registry-based study, the Geocap study considered the addresses at the time of diagnosis for the cases and at the time of inclusion for the controls. It did not cover the whole residential history since conception, and earlier or longer time windows may be more relevant in childhood AL. In the Escale case-control study (data collected in 2003-2004), the household had not moved during the index pregnancy or childhood for $46 \%$ of the controls $<15$ years, and $60 \%$ of those $<5$ years (Amigou et al, 2011). In the present study, the relationship was only observed for children $<5$ years, which might be compatible with a smaller impact of misclassifications, due to moves, of early exposures related to the proximity of VHV-HVOL. The relationship was not observed in children living in the most populated urban Communes.

The present study exclusively addressed the question, recurrent in France, of the risk of childhood AL close to HVOL. If living $<50 \mathrm{~m}$ from HVOL is causally related to AL, it is expected to induce an excess of less than one new case $<15$ years per year in France, under steady conditions of residency close to VHV-HVOL. The distance of the residence from a HVOL is by no means a perfect surrogate for individual exposure to ELF-MF because of the 
proximity of the lines. Individual in situ measurements would be more suitable exposure indicators, provided that they were standardized, accurate and precise measurements, and that no selection bias (and no participation bias) limited their interpretation. Residential proximity of a VHV-HVOL was considered an indicator of increased probability of high residential exposure to ELF-MF, with the hypothesis that other sources of exposure to ELF-MF would be independent of the presence of the line and thus would be distributed similarly for the children living $<50 \mathrm{~m}$ from a VHV-HVOL and those living further away (Schüz et al, 2000; Maslanyj et al, 2007). The study combined stringent voltage $(\geqslant 225 \mathrm{kV})$ and distance $(<50 \mathrm{~m})$ conditions with a high degree of accuracy in the geocoding process, in order to identify the individuals who most probably had the highest exposures to ELF-MF in the population study. Exposure to ELF-MF depends on many sources and, regarding power lines, on many other parameters than distance, particularly current load and type of pylon (also related to the line voltage). Conversely, the distance from VHV-HVOL might also be an indicator of environmental exposures and lifestyle factors related to the vicinity of lines other than ELF-MF.

In a descriptive analysis of studies of ELF-MF exposure in 4452 homes in the United Kingdom (UKCCS, 1999) and 1835 homes in Germany (Schüz et al, 2000), only a small number of dwellings were located within $50 \mathrm{~m}$ of a HVOL (93 homes), 16 of which were close to a 220-400 kV HVOL (Maslanyj et al, 2009). Extremely low-frequency magnetic field exposure $\geqslant 0.4 \mu \mathrm{T}$ was more prevalent in the latter homes $(18.8 \%)$ than in those close to $11-132 \mathrm{kV}$ HVOL (6.5\%), even though the absolute numbers of dwellings with ELF-MF exposure $\geqslant 0.4 \mu \mathrm{T}$ were similar (three and five homes, respectively). Therefore, in this study, the absence of an association close to HV-HVOL lines, where the prevalence of exposed residences is assumed to be lower, is poorly informative with respect to the hypothesis that ELF-MF may have a role in childhood AL.

This hypothesis will be investigated more precisely in a future stage of the Geocap study. RTE is to calculate individual estimates of the exposure to ELF-MF for all the Geocap subjects located close to a HVOL, blind to case/control status. The exposure estimates will take into account the particular characteristics of each of the neighbouring lines (pylons geometry, height and type of cable, ground wires and so on), the average annual current load for each of the identified lines, the time-distribution percentiles of the current load and the particular location of the residence with respect to the closest line spans (Bessou et al, 2013).

This is the first French contribution to the issue of ELF-MF, HVOL and childhood AL. The results are compatible with the first meta-analyses published in 2000 (Ahlbom et al, 2000; Greenland et al, 2000), the recent review by Schüz and Ahlbom (2008) and the most recent meta-analysis summarizing the studies of the last decade (Kheifets et al, 2010). While no underlying biological mechanism has been advanced to date in support of the epidemiological observation (WHO, 2007), the IARC classification of ELF-MF as a possible carcinogen (IARC, 2002) has not been strongly challenged. The study by Draper et al (2005) based on residence at birth and covering more than three decades (1962-1995) revealed associations with longer distances from power lines than previously envisaged, far above the threshold usually recognised as generating ELF-MF greater than background exposures, and with a positive trend with decreasing distance. Extremely low-frequency magnetic fields were estimated secondarily in the same study, and then considered unlikely to be the only explanation (Swanson, 2008; Kroll et al, 2010) for the observed relationship with distance. Overall, the number of exposed newborns was small because five $\mathrm{AL}$ cases and three controls resided at birth within $50 \mathrm{~m}$ of a HVOL (mainly VHV-HVOL) (Draper et al, 2005), and two AL cases and one control were assumed to be exposed to at least $0.4 \mu \mathrm{T}$ (Swanson, 2008). In the present study, we observed no significant trend with decreasing distance to VHV-HVOL.

Recently, in a commentary on the most recent papers by Kroll et al (2010) and Kheifets et al (2010), Schmiedel and Blettner (2010) drew attention to the current limitations of epidemiology with regard to affording new insights in the field and answering questions in the absence of satisfactory biological models. Geocap was designed for quantitative modelling and the study of coexposures, and may thus be considered an appropriate tool for contributing to knowledge in the field.

\section{CONCLUSION}

In conclusion, the present study has generated additional findings, based on a recent nationwide unselected population-based study, that support the hypothesis that living $<50 \mathrm{~m}$ from a 225 or $400 \mathrm{kV}$ HVOL may be associated with an increased incidence of childhood AL. No increase in risk was observed further from those lines and no increase in childhood AL risk was detected within $50 \mathrm{~m}$ of the $63-150 \mathrm{kV}$ HVOL. Model-based estimates of ELF-MF exposures will be used to investigate for potential involvement of ELF-MF in the observed association.

\section{ACKNOWLEDGEMENTS}

This study was supported by the Institut de Veille Sanitaire (InVS), the Agence Nationale de Sécurité Sanitaire de l'Alimentation, de l'Environnement et du Travail (ANSES), the Fondation ARC pour la recherche sur le cancer, the Fondation Pfizer, the Institut National du Cancer (INCa), the Agence Nationale de la Recherche (ANR) and the Cancéropôle Ile de France. It is part of the Investissement d'Avenir HOPE-EPI. The authors are particularly grateful to: (1) Olivier Lamy and Mathieu Carrère from 'GEOCIBLE', who carefully ensured all the geocoding, and IGN, which made available precise maps for the whole country; (2) Magda Tomasini and Laurent Auzet from the 'Institut National de la Statistique et des Etudes Economiques' (INSEE), who conducted the control sampling; (3) Jérôme Bessou and Damien Cougnaud from the French 'Réseau de transport d'Electricité' (RTE), who greatly helped in making available all the needed GIS information on the French high voltage overhead line network; and (4) all the NRCH research assistants who collected the cases' addresses and the paediatric oncology teams for their help in data collection.

\section{DISCLAIMER}

A written contract between RTE and Inserm U1018 team 6 has been concluded and states that team 6 has complete control over the conduct, interpretation and publication of the study. This paper has not been approved by any RTE personnel member other than François Deschamps, who approved it in his capacity as author. The paper does not necessarily represent RTE's views.

\section{REFERENCES}

Ahlbom A, Day N, Feychting M, Roman E, Skinner J, Dockerty J, Linet M, McBride M, Michaelis J, Olsen JH, Tynes T, Verkasalo PK (2000) A pooled analysis of magnetic fields and childhood leukaemia. $\mathrm{Br}$ J Cancer 83: 692-698.

Amigou A, Sermage-Faure C, Orsi L, Leverger G, Baruchel A, Bertrand Y, Nelken B, Robert A, Michel G, Margueritte G, Perel Y, Mechinaud F, 
Bordigoni P, Hémon D, Clavel J (2011) Road traffic and childhood leukemia: the escale study (sfce). Environ Health Perspect 119: 566-572.

Bessou J, Deschamps F, Figueroa L, Cougnaud D (2013) Methods used to estimate residential exposure to $50 \mathrm{~Hz}$ magnetic fields from overhead power lines in an epidemiological study in France. J Radiol Prot 33(2): 349-365.

Clavel J, Goubin A, Auclerc MF, Auvrignon A, Waterkeyn C, Patte C, Baruchel A, Leverger G, Nelken B, Philippe N, Sommelet D, Vilmer E, Bellec S, Perrillat-Menegaux F, Hémon D (2004) Incidence of childhood leukaemia and non-hodgkin's lymphoma in france: national registry of childhood leukaemia and lymphoma, 1990-1999. Eur J Cancer Prev 13: 97-103.

Draper G, Vincent T, Kroll ME, Swanson J (2005) Childhood cancer in relation to distance from high voltage power lines in england and wales: a case-control study. BMJ 330: 1290.

Greenland S, Sheppard AR, Kaune WT, Poole C, Kelsh MA (2000) A pooled analysis of magnetic fields, wire codes, and childhood leukemia. childhood leukemia-emf study group. Epidemiology 11: 624-634.

IARC (2002) Monograph on the Evaluation of Carcinogenic Risks to Humans Non-ionizing Radiation, Part 1: Static and Extremely Low Frequency (elf) Electric and Magnetic Fields/ IARC Working Group on the Evaluation of Carcinogenic Risks to Humans Vol. 80. IARC press: Lyon, France.

Kheifets L, Ahlbom A, Crespi CM, Draper G, Hagihara J, Lowenthal RM, Mezei G, Oksuzyan S, Schüz J, Swanson J, Tittarelli A, Vinceti M, Wunsch Filho V (2010) Pooled analysis of recent studies on magnetic fields and childhood leukaemia. Br J Cancer 103: 1128-1135.

Kheifets L, Oksuzyan S (2008) Exposure assessment and other challenges in non-ionizing radiation studies of childhood leukaemia. Radiat Prot Dosimetry 132(2): 139-147.

Kroll ME, Swanson J, Vincent TJ, Draper GJ (2010) Childhood cancer and magnetic fields from high-voltage power lines in england and wales: a case-control study. Br J Cancer 103: 1122-1127.

Lacour B, Guyot-Goubin A, Guissou S, Bellec S, Désandes E, Clavel J (2010) Incidence of childhood cancer in france: national children cancer registries, 2000-2004. Eur J Cancer Prev 19: 173-181.

Maslanyj M, Simpson J, Roman E, Schüz J (2009) Power frequency magnetic fields and risk of childhood leukaemia: misclassification of exposure from the use of the 'distance from power line' exposure surrogate. Bioelectromagnetics 30: 183-188.

Maslanyj MP, Mee TJ, Renew DC, Simpson J, Ansell P, Allen SG, Roman E (2007) Investigation of the sources of residential power frequency magnetic field exposure in the uk childhood cancer study. J Radiol Prot 27: 41-58.

Mezei G, Kheifets L (2006) Selection bias and its implications for case-control studies: A case study of magnetic field exposure and childhood leukaemia. Int J Epidemiol 35(2): 397-406.

Schmiedel S, Blettner M (2010) The association between extremely low-frequency electromagnetic fields and childhood leukaemia in epidemiology: enough is enough? Br J Cancer 103: 931-932.

Schüz J, Ahlbom A (2008) Exposure to electromagnetic fields and the risk of childhood leukaemia: a review. Radiat Prot Dosimetry 132(2): 202-211.

Schüz J, Grigat JP, Störmer B, Rippin G, Brinkmann K, Michaelis J (2000) Extremely low frequency magnetic fields in residences in germany. distribution of measurements, comparison of two methods for assessing exposure, and predictors for the occurrence of magnetic fields above background level. Radiat Environ Biophys 39: 233-240.

Sermage-Faure C, Laurier D, Goujon-Bellec S, Chartier M, Guyot-Goubin A, Rudant J, Hémon D, Clavel J (2012) Childhood leukemia around french nuclear power plants-the geocap study, 2002-2007. Int J Cancer 131: E769-E780.

Swanson J (2008) Methods used to calculate exposures in two epidemiological studies of power lines in the UK. J Radiol Prot 28: 45-59.

UKCCS (1999) Exposure to power-frequency magnetic fields and the risk of childhood cancer. UK childhood cancer study investigators. Lancet 354: 1925-1931.

WHO (2007) Extremely low frequency fields environmental health criteria. Monograph no 238. available at http://www.who.int/peh-emf/ publications/elf_ehc/en/index.html.

This work is published under the standard license to publish agreement. After 12 months the work will become freely available and the license terms will switch to a Creative Commons AttributionNonCommercial-Share Alike 3.0 Unported License. 